\title{
Sustainable Consumption and Production in Emerging Markets
}

\section{Ming-Lang Tseng}

Lunghwa University of Science and Technology, Taiwan

E-mail tsengminglang@gmail.com

\section{Kim Hua Tan}

Nottingham Business School, Nottingham University, UK

E-mail kim.tan@nottingham.ac.uk

\section{Yong, Geng}

School of Environmental Science and Engineering, Shanghai Jiao Tong University, China

E-mail:ygeng@sjtu.edu.cn

\section{Kannan Govindan}

Center for Engineering Operations Management, Department of Technology and Innovation, University of Southern Denmark, Odense, Denmark

E-mail kgov@iti.sdu.dk

\begin{abstract}
This special issue addresses sustainable consumption and production (SCP) in emerging markets by examining novel methods, practices, and opportunities. The articles present and analyze topdown sustainability efforts as well as bottom-up efforts on firms, supply chain networks, government regulations, and solution methods. This editorial note summarizes the discussions on the firm's operational attributes, sustainable consumption and production practices, and on evaluation and implementation methods. A dominant finding is that the issues of SCP should be explored in different ways within different contexts in emerging countries.
\end{abstract}

Keywords: sustainable consumption and production, emerging market, sustainable supply chain management, institutional pressures 


\section{Introduction}

Achieving sustainable consumption and production (SCP) has emerged as a significant challenge in emerging markets (Tseng et al., 2013). Since the mid-1990s, SCP has become one of the most popular policy making strategies globally (Geels et al., 2015). According to Blok et al. (2016), SCP practices can improve a firm's sustainable performance and may lead to a balanced development of global economic and political systems in a sustainable way. Despite the importance of this approach, however, little research exists on this subject that focuses on the development of new models or on the inclusion of case studies and empirical studies, especially in emerging markets. The purpose of this special issue (SI) is to collect the existing research and latest debates on different approaches for managing sustainable consumption and production. This SI seeks to encourage research that (a) broadens an understanding of SCP, (b) shows how research has evolved in light of accumulated knowledge or in response to specific critiques, and (c) deepens theoretical and practical insights. Authors represented in this SI examine how successfully SCP practices are addressed at firm, supply chain, and national levels. In addition, researchers discuss the nature of the marketplace and some of the various operational strategies employed (Lin et al., 2015; Tseng et al., 2016; Wu et al., 2016).

According to Kearney (2012) and Rauch et al. (2016), emerging markets are those that extend more in terms of either space and/or human resources. With an annual growth rate of nearly $7 \%$, emerging markets demonstrate rapid forward development, reflecting a growth rate that exceeds what is typically found in developed nations. On the other hand, emerging markets still face significant challenges as they try to implement modern sustainable strategies, because in some cases even basic definitions remain unclear. Sustainable consumption and production is considered here as an umbrella term; it includes a wide range of strategies including supplier selection (Kannan et al., 2014), green and lean manufacturing (Thanki et al., 2016; Govindan et al., 2016a), remanufacturing (Xia et al., 2015) and so on. Hence, the term SCP remains, to some extent, a flexible definition. It is accepted that sustainable development is a result of sustainable consumption and production, and that emerging markets are still behind the curve in these areas (Jia et al., 2016; Bouzon and Govindan, 2015). In order to advance a clearer, more rigorous definition of SCP, this SI examines operations management, operations research, economics, marketing, and other domains and studies that pertain to SCP in emerging countries. Countries represented here include China (Hong Kong, Taiwan, and the city of Shanghai), Malaysia, Ghana, the Philippines, Iran, and India. These studies cover different theoretical consumerism streams (Wang and Haze, 2016; Zhu and Sarkis, 2016), apply diverse empirical approaches, operational strategies, and propose methodological solutions. Other studies investigate how emerging markets address firms' SCP challenges, the firms' responses to operations, and how those strategies vary among different countries (Wu et al., 2016; Chan et al., 2016; Akhtar et al., 2016; Wong et al., 2016; Ali and Suleiman, 2016; Zhu, 2016). In addition, other scholars analyze the role of transportation and logistics providers' functions and present different effective models or potential solutions for aligning different supply chain parties to achieve SCP (Tan et al., 2016; Choy et al., 2016; Tseng and Huang, 2016; Zhou et al., 2016). Lastly, several studies present incentives and barriers at the industrial park level (Huang et al., 2016; Kusi-Sarpong et al., 2016; Esfahbodi et al., 2016) and at the government level (Wang et al., 2016; Chung et al., 2016; Luthra et al., 2016; Song et al., 2016).

In general, this SI contributes to knowledge improvement by providing both theoretical 
insights and empirical practices. From the theoretical perspective, the SI aims to develop new insights in SCP; it serves as a useful collection of the best scholarship current available on the topic. From a practice perspective, it addresses some relevant challenges: gaining comprehensive advantages, improving technological capabilities, and concentrating on industrial activities and government regulations. The editorial note is organized as below. Following this introduction, the second section offers a brief summary of the various articles selected for inclusion in this Special Issue. Section 2 details SCP initiatives in emerging countries (including sustainable consumption and production at the firm and supply chain levels), and examines SCP-related regulations and proposed solutions. The third section draws the conclusions of this editorial note.

\section{SCP in emerging countries}

This section discusses sustainable consumption from customer perspectives, sustainable production at the firm and supply chain levels, as well as SCP-related regulations and proposed solutions.

\subsection{Sustainable consumption}

Achieving sustainable consumption requires consumption efficiency improvement and consumption pattern changes. In this regard, technological improvement and customer perception can help reduce resource consumption. More attention to customer perceptions should be paid in order to assess the need for changes of sustainable consumption and related infrastructures. Wang and Haze (2016) indicated that purchase intention is positively influenced by perceived values and negatively influenced by perceived risks when customers purchase remanufactured products in China. Customers remain skeptical about re-manufactured products. Hence, to establish trust between re-manufacturers, their products, and their consumers, it is necessary for firms to set high quality standards for re-manufactured goods and to offer certification of these standards to consumers. Such actions lead to better perceived values, most influenced by quality, followed by cost and green perception. Perceived risks are most influenced by quality and cost that help re-manufacturers and closed-loop supply chain management to prepare the management policies and marketing strategies.

Zhu and Sarkis (2016) proposed that sustainable consumption can be managed through green marketing and green consumerism efforts in China. The conceptual framework has been used to identify gaps based on marketing strategies, industrial sectors, international comparisons, and green consumerism. Marketing and environmental outcomes for green products need to go beyond best practices descriptions and a narrow focus on green packaging.

Green pricing and premium modeling investigation is required at industrial and consumer levels. Promotional message effectiveness and green customer education can be expanded to enhance customer relationship management, and a comparison of green marketing dimensions and their adoption levels across different industrial sectors is a fertile area of research. A comparative understanding of international green consumerism is needed; approaches are needed to reach beyond first-layer cities and to use broader demographic and psychographic variables and scales in order to facilitate future research on green consumerism. In summary, from the customer's perspective, the green market needs to build trust relations with the firms' products and their green operational processes. 


\subsection{Sustainable production at firm level}

Sustainable production focuses on how one firm's capability can be built. Wu et al. (2016) showed that path-dependent learning is the top priority and that manufacturers should consider opportunity-sensing capability and integrative capability simultaneously in the operational process. They proposed interval-valued triangular fuzzy numbers to convert the experts' opinions into comparable measures and used grey relational analysis to facilitate and clarify the weights of eco-innovation under dynamic organizational capability in the Taiwanese light industry.

Chan et al. (2016) examined the mediating effect of green product innovation between the aforementioned pressures and firm performance. They concluded that it is necessary to examine the effects of innovation on the relationship between environmental regulations and firm performance; the moderating effect of environmental dynamism was evaluated on this sensitive relationship. Leadership still plays a role in moving the firm toward sustainable production. Akhtar et al. (2016) scrutinized the links among data-driven and adaptive leadership, non-financial sustainability and financial sustainability using structural equation modelling. Their results indicated that data-driven and adaptive leadership is a key determinant for non-financial sustainability, which in turn contributes to financial sustainability. The leadership continues to play a vital role in the company's financial sustainability. Interaction effects further depict that the firms which apply more data-driven and adaptive leadership practices in agri-food supply chains in the emerging markets tend to be more successful.

Wong et al. (2018) addressed the challenges faced by third party logistics. They used the theoretical lens of market-based and resource-based views to determine if environmental attributes (external) and a firm's competencies (internal) will influence their sustainable competitiveness through strategic emphasis and sustainable consumption and production. Third party logistics adopt both low costs and differentiation strategies and were still able to sustain consumption and production to remain competitive. The firms could look towards innovative transportation infrastructure and service options to strengthen their competitive positions (Lin and Tseng, 2016). With uncertain and changing economic environments, firms would also expect to see more consultations among key people from various functions in the organizations. Hence, sustainable production could be adopted as a a pattern for operations. The study of Ali and Suleiman (2016) explored and evaluated the relationships and links between standard food production practices and the principles of sustainable production. Their findings can help understand the synergies between standard production practices and sustainable production principles. They clarify whether halal food production is successful in capturing aspects of sustainable development, and they identify opportunities for small- and medium-sized firms to engage in sustainable initiatives with minimal cost.

\subsection{SCP in supply chain networks}

There are certain SCP pressures at the government, industrial, and firm levels. For instance, Zhu (2016) studied the institutional pressures (coercive, normative, and mimetic) that drive manufacturers to implement sustainable production, and he compared those pressures against those from industrial zone practitioners. This study revealed that normative pressure motivates most sustainable production practices except land saving practices without the need of support from industrial zones. Coercive pressure can bring sustainable production practices related to resource conservation (including water, land, and energy) while support from industrial zones is 
needed for land and energy saving practices. Finally, mimetic pressure only motivates SP practices on land saving only, but support from industrial zones is still necessary. Practices on the efficient consumption of materials, water, energy, and land require support from industrial zones to examine motivation mechanisms for SP practices among manufacturers, especially in emergent economies.

Huang et al. (2016) found that industrial parks are essential communities for promoting sustainable development due to their intensive energy consumption and greenhouse gas emissions. They proposed that an optimization of the energy structure, a transformation of infrastructure, and an auditing of energy consumption and greenhouse gas emissions are feasible approaches. Their study examined industry symbiosis and energy saving in the building sector to lower carbon emissions in Caohejing Industrial Park, China. This study provided a useful case on how to initiate low carbon efforts at the industrial park level so that such parks can make necessary changes towards sustainable post-fossil carbon societies. Kusi-Sarpong et al. implied that the relationship between suppliers and buyers may lead to joint green capabilities and competencies development, leading to collaborative and competitive advantages by integrating strategic suppliers into early joint environmental discussions and learning activities. They applied integrated fuzzy decision making trial and evaluation laboratory and analytical network processes for their evaluation of limiting the interdependencies within GSCM attributes in Ghana's mining industry.

Esfahbodi et al. (2016) examined the impact of SSCM adoption on environmental and cost performance within two emerging markets using a multiple regression analysis. The results showed that there are similarities between two emerging economies, and that the adoption of SSCM practices can help improve the environmental performance of both Chinese and Iranian manufacturers. However, such practices do not necessarily lead to improved cost performance. They suggested that firms operating within emerging markets need to undertake SSCM initiatives with a broader consideration of their financial bottom line in order to minimize trade-offs between the environmental and cost performances.

\subsection{SCP-related regulations}

SCP has been regulated in emerging countries. Wang et al. (2016) analyzed the effects of carbon tariffs on total carbon emissions and global social welfare and concluded that (1) carbon tariffs greatly threaten the survival of developing-country firms in those markets; (2) both total carbon emissions and global social welfare are reduced with the implementation of carbon tariffs; and (3) textile firms in developing countries should make efforts to choose the appropriate technologies for emissions reduction. Similarly, another study conducted by Chung et al. (2016) focused on the interaction effects between institutional constraints and managerial intentions. They found that effective regulatory enforcement can have either a facilitating or an inhibiting role on sustainable performance for actors in different organizations, depending on individual managerial orientations. They also found that the effect of proactive intentions on performance can be greatly enhanced under a supportive institutional environment. They provide a case study in which management perceived a low level of regulation constraints in a Cleaner Production Program in China.

Luthra et al. (2016) investigated government support policies and identified key barriers on adopting SCP initiatives in the supply chain using the analytical hierarchy process and a sensitivity 
analysis-based structural model. In addition, Song et al. (2016) combined a super-efficiency slackbased measurement model and a data envelopment analysis model to calculate the environmental efficiencies of highway transportation systems. The results showed that the overall level of environmental efficiency of highway transportation systems in China was not optimal; they identified great differences between different regions. Most regions had problems with excessive energy consumption and motor vehicle pollution. Such areas need to control both energy consumption and pollutant emissions so atmospheric pollution can be mitigated.

These studies analyzed correlations among environmental efficiency, nitrogen oxide efficiency, and particulate matter efficiency so that the state of energy consumption and atmospheric pollution on the highway transportation systems in China can be further researched.

\subsection{Proposed solutions}

Previous studies on SCP focused on theoretical or methodological approaches (Lin et al., 2015, Tan et al., 2016). For instance, Tan et al. (2016) developed adaptation strategies to ensure the resilience of industrial activities to various perturbations that may result from climate change. The inherent complexity of such systems makes decision-making for risk management a nontrivial task that is best facilitated with the aid of mathematical models. The firms' input-output model has been used extensively to model production systems. Hence, a fuzzy linear programming firms' input-output model is developed to determine optimal adjustments in production levels of multiproduct systems when a crisis is induced by a loss of resource inputs. This allows for adjustments that are equitable for different decision-makers who may comprise an industrial complex or a supply chain on the effect of water shortage on an aluminum production system. This study is particularly important to deal with production systems since its holistic objective is to create sustainable supply chains to respond to all stakeholders within the value chain. Choy et al. (2016) presented a study in a Chinese chemical industry in which firms are urged to improve the quality of chemical products while minimizing the environmental impacts during production. They proposed a recursive operations strategy model for assessing the competitive priorities and policies with the use of artificial intelligence that included casebased reasoning and fuzzy logic to manage the operations functions. The results provide direct guidelines for reducing and minimizing waste to achieving continuous improvement and determining the optimal production process conditions for avoiding unnecessary energy consumption.

In the decision-making process, Lin et al. (2015) presented an approach on sustainable development based on a balanced scorecard mode that prioritizes attributes by a multihierarchical structure under uncertainty. Tseng and Huang (2016) proposed a rough set of decision rules based on conditions and decision hierarchical attributes; these rules contribute a novel solution to generate a successful sustainable tourism study. Sustainable tourism service and energy consumption have become contemporary trends due to environmental and energy concerns in global tourism industry. Zhou et al. (2016) developed a forecasting model that can predict the quantity, time, and probability of product returns, recyclable parts/components/materials, and disposal quantities using a graphical evaluation and review technique. They translate the re-manufacturing operational process into a stochastic network using generic 8-step processes to structure the return products and re-manufacturing network on forecasting printer re-manufacturing. The model can predict return quantity, time, or 
probability, and it may forecast them simultaneously.

\section{Learning points in this special issue}

Collective studies on the topic of SCP in emerging countries are uncommon at this point. Hence, this SI has purposefully collected possible solutions, models, and methods to effectively explore complicated situations from multiple levels and to approach sustainable consumption in emerging countries from a variety of perspectives. As a result, this $\mathrm{SI}$ provides various insights into state-of-the-art studies in the SCP field. Some of the key findings are highlighted. One main finding indicates that SCP is not merely a top-down effort (government, industries, and firms). Rather, bottom-up efforts (firms, industries, and government) are also needed from customers, manufacturers, and suppliers as voluntary practices. In addition, the innovative ideas proposed in this SI may provide feasible solutions for SCP from multiple perspectives regardless of the level of the firm in the global supply chain. Those identified attributes might provide valuable policy insights to decision makers, who might then be more confident in making appropriate policies to promote and implement SCP in emerging countries. Although various factors are discussed and explored in this $\mathrm{SI}$, the study emphasizes the primary role of leadership to push through environmental, economic, and social concerns (called the "triple bottom line," TBL) coming from government, industrial, and firm levels. However, in addition to the major useful findings presented here, this SI provides possibilities for future enhancements in the field of SCP, which encourage more in-depth scholarship on SCP practices in emerging markets. Some of the key general possible future enhancements available from the study are discussed below.

As mentioned earlier, leadership plays a vital role in the implementation of SCP in emerging markets. But there is a general lack of automated technology and knowledge in data-related education which hinders sound leadership practices for policy making. Hence, ample opportunities exist to explore these top level management skills, including shortage, data quality, and other cyber-security issues under the concern of efficient leadership.

- One of the key successful factors in SCP is green innovation, but in terms of emerging markets, exactly what constitutes green innovation is still unclear. Hence, there is a significant need for studies to explore the various kinds of pressures that inhibit green innovation, including institutional perspectives. In addition, it is possible to extend the studies on the relationship between environmental dynamism and green innovation pressures under conceptual theories.

- While some studies have focused on institutional pressures of SCP, little attention has been devoted to the important normative pressure. Among emerging contexts, firms are generally not strong enough to explore these kinds of normative pressures; hence, normative pressures, especially in emerging markets, remains ripe for future study.

- Among the various pressures of SCP, governmental incentives have a great impact on a firm's voluntary involvement and implementation. But no clear research exists to sort out which type of incentives could be most successful and how short- term incentives might transform to long-term successful strategies for SCP.

- Particularly in emerging markets, government support is most important for the application of SCP. However, in most emerging markets, institutional contexts are prioritized with respective to time. Hence, the possibility exists to explore the varying effectiveness of 
environmental laws and prevention measures with regard to geography. This study will encourage upcoming firms to examine their own methods to improve sustainable performance through SCP.

- Many studies reported the cost in SCP, but there is still room to explore the inclusion of other economic factors such as sales performance and their relationships with the implementation. This focus area would provide useful insights on overall performance of the firm regardless of its position in the supply chain. Small- and medium-scale enterprises (SMEs) are deliberately trying to balance the sales performances and sustainable strategies particularly in emerging markets, so this kind of study would certainly promote SCP among SMEs.

- Further study is needed on the drivers and barriers of SCP with multi stakeholder and interorganizational perspectives. A clear understanding of these elements will assist decision makers to emphasize driving factors and to eradicate barriers involved in the implementation. Also, this topic might be further extended with benchmarking studies by comparing developing and developed nations under the concern of SCP implementation.

- A main success of SCP has been on lowering emissions, but it has become evident that emerging markets are more exposed to threatening emissions from industries and highway transportations. Emissions in emerging markets, of course, contribute to global emissions. With few strict national policies and incomplete or non-existent monitoring operating in emerging markets, a model for new policies might be constructed with a contemporary focus along with a governing tool for existing policies.

- A very limited focus was paid to multi-period and multi-regional supply chains in terms of its implementation, so many opportunities exist within this field of study. Hence, future enhancements of this multi-level supply chain concerning SCP create awareness on low level and least tier suppliers in order to compete with modern globalization.

- Recently proposed carbon tariff plans are considered as a key challenge in addition with the existing issues involved in the SCP implementation in emerging markets. However, few studies adopted the focus of developing markets. Hence, more exploration on the impact of these foreign policies on implementation is needed, and more strategies to balance current and future tariff policies should be proposed.

- The precise inclusion of terms such as green marketing, green consumerism, and 4R (redirection of customer needs, re-consumption, reorientation of marketing mix, reorganization) within the perspective of SCP would improve opportunities for future research in emerging contexts.

- In addition to conceptual perspectives, some methodological explorations might also provide sound implementation. Tools such as multi-criteria decision making, optimization techniques, and statistical analysis, which have already been successfully applied in various sustainable studies (Govindan et al., 2016b; Sun et al., 2013; Shaharudin et al., 2015; Govindan et al., 2015; Lin and Tseng 2016) may provide a foundation for future research.

\section{References}

1. Akhtar, P., Tse, M., Khan, Z., Rao-Nicholson, R. (2016). Data-driven and adaptive leadership contributing to sustainability: global Agri-food supply chains connected with emerging markets. International Journal of Production Economics (Article in Press)

2. Ali, M.H., Suleiman N. (2016). Sustainable food production: insight of Malaysian Halal small 
and medium sized enterprises. International Journal of Production Economics (Article in Press)

3. Blok, V., Long, T. B., Gaziulusoy, A. I., Ciliz, N., Lozano, R., Huisingh, D., ... \& Boks, C. (2015). From best practices to bridges for a more sustainable future: advances and challenges in the transition to global sustainable production and consumption: Introduction to the ERSCP stream of the Special volume. Journal of Cleaner Production, 108, 19-30.

4. Bouzon, M., \& Govindan, K. (2015). Reverse Logistics as a Sustainable Supply Chain Practice for the Fashion Industry: An Analysis of Drivers and the Brazilian Case. In Sustainable Fashion Supply Chain Management (pp. 85-104). Springer International Publishing.

5. Chan, H.K. Yee, R.W. Y. , Dai, J., Lim, M.K. (2016). The Moderating Effect of Environmental Dynamism on Green Product Innovation and Performance. International Journal of Production Economics (Article in Press)

6. Choy, K.L., Ho, G.T.S., Lee, C.K.H., Lam, H.Y., Cheng, S.W.Y., Siu, P. K.Y., Pang, G.K.H., Tang, V., Lee, J.C.H., Tsang, Y.P. (2016). A recursive operations strategy model for managing sustainable chemical product development and production. International Journal of Production Economics (Article in Press)

7. Chung, L., Lo, C.W.H, Li, P.H.Y. (2016). The Interaction Effects of Institutional Constraints on Managerial Intentions and Sustainable Performance. International Journal of Production Economics (Article in Press)

8. Esfahbodi, A., Zhang, Y., Watson, G. (2016). Sustainable supply chain management in emerging economies: Trade-offs between environmental and cost performance. International Journal of Production Economics (Article in Press)

9. Geels, F. W., McMeekin, A., Mylan, J., \& Southerton, D. (2015). A critical appraisal of Sustainable Consumption and Production research: The reformist, revolutionary and reconfiguration positions. Global Environmental Change, 34, 1-12.

10. Govindan, K., Jha, P. C., \& Garg, K. (2016a). Product recovery optimization in closed-loop supply chain to improve sustainability in manufacturing. International Journal of Production Research, 54(5), 1463-1486.

11. Govindan, K., Garg, K., Gupta, S., \& Jha, P. C. (2016b). Effect of product recovery and sustainability enhancing indicators on the location selection of manufacturing facility. Ecological Indicators, 67, 517-532.

12. Govindan, K., Jafarian, A., \& Nourbakhsh, V. (2015). Bi-objective integrating sustainable order allocation and sustainable supply chain network strategic design with stochastic demand using a novel robust hybrid multi-objective metaheuristic. Computers \& Operations Research, $62,112-130$.

13. Huang, B., Jiang, P., Wang, S., Zhao, J., Wu, L. (2016). Low carbon Practice in Caohejing HighTech Industrial Park of Shanghai, China. International Journal of Production Economics (Article in Press)

14. Jia, P., Govindan, K., Choi, T. M., \& Rajendran, S. (2015). Supplier selection problems in fashion business operations with sustainability considerations. Sustainability, 7(2), 1603-1619.

15. Kannan, D., de Sousa Jabbour, A. B. L., \& Jabbour, C. J. C. (2014). Selecting green suppliers based on GSCM practices: Using fuzzy TOPSIS applied to a Brazilian electronics company. European Journal of Operational Research, 233(2), 432-447.

16. Kearney, C. (2012). Emerging markets research: Trends, issues and future directions. Emerging Markets Review, 13(2), 159-183. 
17. Kusi-Sarpong, S., Sarkis, J., Wang, X. (2016). Assessing Green Supply Chain Practices in the Ghanaian Mining Industry: A Framework and Evaluation. International Journal of Production Economics (Article in Press)

18. Lin, M.H., Hu, JY., Tseng M.L., Chiu, ASF., Lin, C.Y. (2015) Sustainable development in technological and vocational higher education: Balanced scorecard measures with uncertainty. Journal of Cleaner Production 120(1), 1-12

19. Lin, Y.H., Tseng, M.L. (2016). Assessing the competitive priorities within sustainable supply chain management under uncertainty. Journal of Cleaner Production 112,2133-2144

20. Luthra, S., Mangla, S.K., Xu, L., Diabat, A. (2016). Using AHP to Evaluate Barriers in Adopting Sustainable Consumption and Production Initiatives in Supply Chain. International Journal of Production Economics (Article in Press)

21. Rauch, E., Dallasega, P., \& Matt, D. T. (2016). Sustainable production in emerging markets through Distributed Manufacturing Systems (DMS). Journal of Cleaner Production, 135, 127138.

22. Shaharudin, M. R., Govindan, K., Zailani, S., \& Tan, K. C. (2015). Managing product returns to achieve supply chain sustainability: an exploratory study and research propositions. Journal of Cleaner Production, 101, 1-15.

23. Song, M., Zheng, W., Wang, Z. (2016). Environmental efficiency and energy consumption of highway transportation systems in China. International Journal of Production Economics (Article in Press)

24. Sun, X., Li, Y., Govindan, K., \& Zhou, Y. (2013). Integrating dynamic acquisition pricing and remanufacturing decisions under random price-sensitive returns. The International Journal of Advanced Manufacturing Technology, 68(1-4), 933-947.

25. Tan, R.R., Aviso, K., Cayamanda, C., Chiu A., Promentilla, M., Ubando, A., Yu, K. (2016). A Fuzzy Linear Programming Enterprise Input-Output Model for Optimal Crisis Operations in Industrial Complexes. International Journal of Production Economics (Article in Press)

26. Thanki, S., Govindan, K., \& Thakkar, J. (2016). An investigation on lean-green implementation practices in Indian SMEs using analytical hierarchy process (AHP) approach. Journal of Cleaner Production, 135, 284-298.

27. Tseng M.L., Tan, K., Chiu, A.S.F. (2016). Identifying the competitive determinants of firms' green supply chain capabilities under uncertainty. Clean Technology and Environmental Policy 18(5), 1247-1262

28. Tseng, M.L., Chiu, A.S.F., Tan, R.R., Manalang, A.B. (Jan. 2013). Sustainable consumption and production for Asia: Sustainability through green design and practice. Journal of Cleaner Production 40, 1-5

29. Tseng, T.L., Huang, C.C. (2016). Sustainable Service and Energy Provision Based on Agile Rule Induction. International Journal of Production Economics (Article in Press)

30. Wang, M., Liu, J., Chan, C.L., Choi, T.M., Yue, X., (2016). Effects of Carbon Tariffs Trading Policy on Duopoly Market Entry Decisions and Price Competition: Insights from Textile Firms of Developing Countries. International Journal of Production Economics (Article in Press)

31. Wang, Y. and Haze, B.T. (2016). Consumer Product Knowledge and Intention to Purchase Remanufactured Products. International Journal of Production Economics (Article in Press)

32. Wong, W.P., Soh, K.L., Chong, C.L. (2016). Differentiated Service Consumption and Low Cost Production: Striking a Balance for a Sustainable Competitive Advantage in Malaysia. 
International Journal of Production Economics (Article in Press)

33. Wu, K.J., Liao, C.J., Chen, C.C., Lin, Y.H., Tsai, C.F.M. (2016). Exploring eco-innovation in dynamic organizational capability under incomplete information in the Taiwanese lighting industry. International Journal of Production Economics (Article in Press)

34. Wu, K.J., Liao, C.J., Tseng M.L., Chiu, A.S.F., Chiu, K.K.S. (2016). Using interval-valued triangular fuzzy numbers - grey relational analysis to evaluate sustainable supply chain management under uncertainty. Industrial Management and Data system 116(4), 777- 800

35. Xia, X., Govindan, K., \& Zhu, Q. (2015). Analyzing internal barriers for automotive parts remanufacturers in China using grey-DEMATEL approach. Journal of Cleaner Production, 87, 811-825.

36. Zhou, A., Xie, J., Gu, X., Lin, Y., Leromonachou, P., Zhang, X. (2016). Forecasting Return of Used Products for Remanufacturing Using Graphical Evaluation and Review Technique (GERT). International Journal of Production Economics (Article in Press)

37. Zhu, Q. (2016). Institutional pressures and support from industrial zones for motivating sustainable production among Chinese manufacturers. International Journal of Production Economics (Article in Press)

38. Zhu, Q., Sarkis, J. (2016). Green Marketing and Consumerism as Social Change in China: Analyzing the Literature. International Journal of Production Economics (Article in Press) 